\title{
Código de ética em Psicologia e ética de inspiração fenomenológico-existencial: um diálogo atual e necessário
}

\author{
Code of ethics in Psychology and ethics of \\ existential-phenomenological inspiration: a \\ current and necessary dialogue
}

\section{Danielle de Gois Santos Caldeira' (1) Elza Maria do Socorro Dutra ${ }^{2}$ (1) Cíntia Guedes Bezerra ${ }^{3}$ (1)}

\author{
${ }^{1}$ Autora para correspondência. Universidade do Porto. Porto, Portugal. danielledegois.psi@gmail.com \\ 2-3 Universidade Federal do Rio Grande do Norte (Natal). Rio Grande do Norte, Brasil. elzadutra.rn@gmail.com, cintiaguedesbezerra@gmail.com
}

\begin{abstract}
RESUMO | OBJETIVO: O presente artigo pretendeu construir reflexões sobre ética a partir do código de ética da Psicologia e uma ética fenomenológico-existencial, inspirada na Fenomenologia de Martin Heidegger, e em seus estudos sobre Ontologia. MÉTODO: $O$ artigo insere-se na modalidade de pesquisa qualitativa, teórica, de natureza original, exploratória e descritiva, cujo método de investigação resgata na fenomenologia hermenêutica heideggeriana uma leitura compreensiva da ética a partir dos estudos de textos canónicos referentes ao tema da ética e dos códigos deontológicos que regulamentam e apoiam profissões, por exemplo, o código de ética da Psicologia. Possibilidades metodológicas de leitura compreensiva, assentes no método fenomenológico, ressaltam que o círculo hermenêutico heideggeriano não admite que condições prévias para descrição e compreensão dos fenômenos sejam claras e inalteráveis. Assim, as possibilidades metodológicas articulam conjuntamente componentes do círculo hermenêutico: posição prévia, visão prévia e concepção prévia no sentido de aproximar-se da provisoriedade do fenômeno da ética. DISCUSSÃO: Os objetivos deste estudo são demonstráveis no problema investigado: como são possíveis reflexões sobre a ética na Psicologia desde diálogos entre código de ética em Psicologia e uma ética fenomenológico-existencial? Assim, admitimos ética distinta de moral e problematizamos o modo usual como ética é resumida, na Psicologia, ao Código de ética, ampliando nossas reflexões quanto aos modos de sermos éticos, bem como, privilegiando aproximações ao fenômeno da ética. CONSIDERAçõES FINAIS: Este trabalho aponta outros modos de refletir sobre a ética e contribui para a aproximação compreensiva da ética como tema a ser priorizado nas práticas da Psicologia, inclusive, aproximarmo-nos da ética do cotidiano das relações humanas.
\end{abstract}

PALAVRAS-CHAVE: Ética. Código de Ética. Fenomenologia Existencial. Psicologia.
ABSTRACT | OBJECTIVE: This article intended to build reflections on ethics from the Psychology code of ethics and Existential Phenomenological ethics, inspired by Martin Heidegger's Phenomenology and in his studies on Ontology. METHOD: The article inserts in the qualitative, theoretical, original, exploratory, and descriptive research modality, whose research method rescue in Heidegger's hermeneutic phenomenology a comprehensive reading of ethics from the studies of canonical texts on the theme of ethics and the deontological codes that regulate and support professions, for example, the code of ethics of Psychology. Methodological possibilities for comprehensive reading settled on the phenomenological method emphasize that the Heideggerian hermeneutic circle does not admit that prior conditions for describing and understanding phenomena are clear and unalterable. So, the methodological possibilities seek articulate components of the hermeneutic circle: previous position, previous vision, and previous conception in the sense of approaching the provisionality of the phenomenon of ethics. DISCUSSION: The objectives of this study are demonstrable of the investigated problem: how are possible reflections on ethics in Psychology from dialogues since a code of ethics in Psychology and existential-phenomenological ethics? So, we admit ethics distinct from morals and problematize the usual way in which ethics is summarized, in Psychology, by the Code of Ethics, expanding our reflections on the ways of being ethical and privileging approximations to the phenomenon of ethics. FINAL CONSIDERATIONS: This work points out other ways of reflecting on ethics and contributes to a comprehensive approach to ethical issues to be prioritized in Psychology practices, including approaching the ethics of everyday human relations.

KEYWORDS: Ethics. Code of Ethics. Existential Phenomenology. Psychology. 
A partir do nomear do presente título, uma questão pode ser endereçada: por que unir, em diálogo, ética e código de ética da Psicologia? A leitura proposta a partir do encontro entre ética e código elege como necessário discernir que ética e código de ética da Psicologia não são sinônimos. Todavia, frequentemente, estas noções são equiparadas e estes movimentos são demonstrativos do desconhecimento quanto às implicações que cada noção carrega. Ressaltamos, inclusive, que usualmente o termo código deontológico não é de declaração usual, apesar de na maior parte das vezes os códigos de ética que legislam as profissões, por exemplo, na Psicologia, tratam-se de códigos deontológicos cuja principal designação dedica-se a regular, orientar e esclarecer direitos e deveres aos quais o profissional deve levar em consideração na sua atuação profissional (Amendola, 2014; Caldeira, 2019).

A problemática que nos dispomos a investigar envolve-se na seguinte compreensão: como são possíveis reflexões sobre a ética na Psicologia a partir de diálogos entre código de ética em Psicologia e uma ética fenomenológico-existencial? Para tanto, iniciemos pelo termo em comum: ética.

Ética, no presente artigo, será circunscrita dentro do âmbito da Psicologia a partir do código de ética profissional. Discutir sobre ética e código não se resume a dizer que a ética ultrapassa o código de ética profissional. Igualmente, é insuficiente manifestar estranheza quanto à complexidade pertencente aos citados, pois não são assuntos que interessem ou desinteressem, em exclusivo, a um grupo, isto seria equivalente a delegarmos aos interessados a tutela quanto à observância do nosso existir uns-com-os-outros. Este último argumento serviria para a oficialização de que a condição humana carrega em si uma força que precisa ser vigiada e penalizada.

No cotidiano e no exercício das profissões nem sempre é possível encontrar de maneira clara a expressão código deontológico da profissão, o mais comum, como se verifica na Psicologia, ciência e profissão no Brasil, é ao aludir o código, lê-se a expressão: código de ética profissional da Psicologia', contudo, o que encontramos na Psicologia brasileira é um código de ética que se trata de um código deontológico. Esta maneira simplificada de nomear carrega consigo uma brevidade quanto ao exercício de refletir e à vigência de normas, além disso, remete, simultaneamente, a uma generalização, logo, uma redução compreensiva da ética.

Neste artigo, adotamos como foco compreender e refletir ética com base em diálogos com o código, atualizando a importância de não reduzir ética ao conjunto de regras que regulamenta profissões como a Psicologia. A urgência desse debate diz respeito à crescente ameaça de anulamento do exercício reflexivo, suscitado pela ética, em prol da vigência de procedimentos que flexibilizam nosso compromisso de zelo pelo modo como habitamos o mundo, tal como foi observado por Sá (2016), Sousa (2016), Mattar (2017), e Caldeira (2019).

O fato de a ciência Psicologia conviver com o desafio de se garantir científica ao mesmo tempo em que se alimenta de contingências não mensuráveis e apreensíveis, tal como podemos encontrar nas ciências da natureza e exatas, segundo Caldeira e Dutra (2018), faz do exercício compreensivo aqui proposto uma oportunidade de demonstração do método e da orientação fenomenológica heideggeriana para as humanidades. Desta forma, a orientação que inspira a leitura proposta, apoiada na produção de Martin Heidegger, rompe com a priorização por explicações e interpretações como meios de análise ao modo como convivemos e lidamos com restrições de possibilidades, no tocante a atualizarmos nossa condição de ser-projeto, apesar dos apelos para que entes humanos hajam semelhante a dados passíveis de averiguação e adequação. Para tanto, o modo que privilegiamos para sensibilizar os diálogos sobre ética refletem um percurso teórico sobre o tema e que acompanham toda a construção do artigo, com especial atenção, na seção Caminhos possíveis de diálogo com a ética. Nesta seção, nos propomos a uma retrospetiva histórica da ética, levando em consideração alguns marcos históricos que suscitaram

\footnotetext{
1 “A missão primordial de um código de ética profissional não é de normatizar a natureza técnica do trabalho e sim, a de assegurar, dentro dos valores relevantes para a sociedade e para as práticas desenvolvidas, um padrão de conduta que fortaleça o reconhecimento social daquela categoria" (Código de Ética de Psicologia, 2005, p. 5).
} 
maior interesse ao tema da ética e, especialmente, ressaltando nossa leitura de uma ética de inspiração fenomenológico-existencial.

Neste artigo, o interesse em atualizar e demonstrar a importância do diálogo entre ética e código, inspirado na Fenomenologia Hermenêutica de Martin Heidegger, ressalta o modo como tecemos nossa compreensão apoiados no método fenomenológico. Método não está circunscrito em nossa proposição a uma seção no desenvolvimento de pesquisa. A noção de método defendida não remete apenas a um atributo que propicie a replicação do estudo de forma universalizante, e sim, inspira a promoção de outros exercícios compreensivos contribuindo com a produção de conhecimento de práticas psicológicas e com a compreensão de relações humanas. O método fenomenológico, a partir de Heidegger (1979), revela-se uma proposição quanto ao modo de nos posicionarmos e que, neste artigo, situamos esta proposição frente a ética e nossas requisições por ela.

O método, apoiado nesta orientação filosófica para o desenvolvimento da presente leitura compreensiva evidencia a dinâmica circular entre descrição e investimento de sentido em que nos encontramos envolvidos, a semelhança do que nos possibilita o círculo hermenêutico (Heidegger, 1979; Maux \& Dutra, 2020). Uma vez que somos constituídos pela possibilidade de pré-compreensão (Heidegger, 1979, 1987/2009, 1927/2012) faz-se relevante destacar, que o método fenomenológico não condiz a um uso, e sim, uma orientação para investigações teóricas ou práticas. Os exercícios de compreender e de refletir sobre o nosso modo de estar-no-mundo, orientados pela fenomenologia heideggeriana, abrem caminhos cujos fundamentos anunciam que em nosso constituir enquanto entes humanos são possíveis estratégias que nos ambientem a construir sentidos e nos façam romper com o caráter naturalizado ao qual nos habituamos. Especificamente, para o trabalho aqui desenvolvido, manifesta-se convite para não depositar na ética um caráter de economia de investimento de vida, como se fosse uma solução genérica, espécie de entrega à ética de um caráter de constructo que soluciona problemas, somente pelo fato de ser aludida.
Nesta ocasião, ética é retomada através de sua evidenciação nos códigos, e igualmente, discutimos implicações da ética quanto ao modo coletivo/ singular que nos assiste.

Algumas perguntas reverberam na continuidade do artigo, a partir do anúncio do título: por que ética? 0 que traz de novidade e necessidade para se discutir sobre ética e códigos? Estas questões são proponentes de outras frentes importantes neste trabalho, tal como, objetivos que nos orientam a investigar: as desnaturalizações, enquanto recurso, por exemplo, desde à formulação de questões sobre o fenômeno ética que abrem precedentes para confundirmos ética e moral, e o questionamento sobre a condição de obviedade da ética que, na maior parte das vezes, faz com que esta passe despercebida quanto ao seu caráter implicativo, ou seja, seu compromisso de posicionamento.

A Psicologia, no exercício de oferecer auxílio/ajuda à vida humana, suscita questões às quais referimos enquanto instigantes para compreendermos ética, por exemplo: como habitamos o mundo? Como convivemos? Estar disponível para estas questões, a partir do saber da (ciência e profissão) Psicologia, é expressão do modo como a fenomenologia heideggeriana contribui para inaugurarmos outro pensar, que avança além de identificar e explicar, guiando-nos a compreender os modos de estarmos no mundo, a cada vez, com mais apropriação.

Na presente leitura, a ética é deslocada de uma posição que a reduz a uma matéria ou disciplina, bem como a uma caracterização da ética compondo locução adjetiva, como se ética fosse síntese referindo-se a uma qualificação de algo ou alguém, por exemplo, humanos éticos, para a elucidação da ética como constitutiva do modo como nos humanizamos e nos relacionamos uns com os outros.

Refletir e construir estratégias a fim de aproximar ética do modo como vivemos/convivemos suscita percorrermos caminhos compreensivos da ética. Estes caminhos, apoiados na fundamentação fenomenológica heideggeriana, são compostos na circularidade do método fenomenológico heideggeriano.

${ }^{2}$ Em Seminários de Zollikon, Heidegger afirma que a Psicologia oferece ajuda. 


\section{A circularidade do método fenomenológico heideggeriano}

O percurso metodológico no qual nos apoiamos na investigação/compreensão para os temas propostos se baseia na clínica psicológica fenomenológico-existencial e na fenomenologia hermenêutica de Martin Heidegger. Para esta caminhada, com base na circularidade do método fenomenológico heideggeriano envolvendo posição prévia, visão prévia e concepção prévia (Heidegger, 1979, 1927/2012; Maux \& Dutra, 2020), a investigação dos temas teve início com questionamentos quanto ao lugar da ética como expressão de cuidado, decorrentes da prática clínica psicológica e da docência em Psicologia. Contudo, ao inquirir sobre o lugar da ética e como decorre sua relação com os instrumentos normativos, confrontamos a procura por fundamentação epistemológica como apoio necessário, nem sempre evidente, para desenvolver e aproximar ética da dinâmica científica e profissional da Psicologia dinamizando, desta forma, a circularidade de sentido que nos constitui.

A partir de pesquisas exploratórias e descritivas de conteúdo atestamos que ética, antes de ser tema para a Psicologia, encontra a sua origem na Filosofia, tal como Caldeira (2019) na revisão de literatura de sua pesquisa defendeu. Considerando que há uma extensa e complexa História de Ética na Filosofia, a qual demonstraremos na seção Caminhos possíveis no diálogo com a ética, ao adotar o exercício compreensivo/reflexivo como convite para investigar a ética, observamos ao nos determos ao tema a necessidade de adotar critérios, inaugurar diálogos e alcançar desdobramentos. Estes componentes integram uma circularidade dentro da fenomenologia heideggeriana e mobilizam um inquietar-se graças ao não facultado modo de se apresentar dos fenômenos e de seus desfechos, em vista de desdobramentos.

O trabalho que envolve a circularidade fenomenológica é singular pelo caráter não estagnado de seus componentes: posição prévia, visão prévia e concepção prévia, conforme Azevedo (2013). Logo, a dinâmica compreensiva que envolve a investigação deste tema provoca sensibilidade, abertura às relações e desdobramentos do tema quanto à dimensão de vida à qual fazemos parte e nem sempre percebemos, porquanto, muitas vezes estamos ocupados em sermos eficazes, precisos, empenhados com intenções de que os caminhos de investigação obedeçam sempre às mesmas condições de desenvolvimento a fim de serem replicados.

O método segue a proposta de evidenciar os fenômenos e, por sua vez, oferece modo de leitura de mundo a partir de sua condição de desvelamento. Igualmente mobiliza diferenciação de maneira que não há comportamentos e pensamentos à espera de serem descobertos. O tracejar que percorre o método, segundo Heidegger (1979), é o próprio revelar daquilo que está sendo construído, isto é, o método se revela caminho em construção. Uma oportunidade é inaugurada pela fenomenologia hermenêutica de Martin Heidegger: harmonizar a valorização expressa em forma de compreensão das experiências e a investigação ao fundamento. Assim, aquilo que nos constitui, segundo o filósofo, é um demonstrativo do cerne existencial que nos contempla. No entanto, na maioria das vezes, é de difícil apreensão, restando-nos propor a análise de documentos do legado heideggeriano, no qual o filósofo uniu esforços para compartilhar suas reflexões sobre o existir e assim expor/compartilhar compreensões de questões da existência, juntamente com temas requisitantes de posicionamentos cotidianamente.

O método, a partir da fenomenologia heideggeriana, confronta-nos com a verdade, trata-se da verdade desveladora heideggeriana a qual expõe a essência da verdade que, por sua vez, se distingue de verdade/adequação. ${ }^{3}$ Segundo Heidegger (1987/2009), “(...) método significa o caminho no qual o carácter do campo a ser conhecido é aberto e limitado" (p.143).

\footnotetext{
${ }^{3}$ Heidegger (1987/2009) chamou atenção aos interessados no método fenomenológico quanto a necessidade de um outro pensar distinto ao modo como homens e mulheres são incentivados, pelas ciências modernas. No modo de pensar ao qual fomos/somos acostumados, admitimos como fonte de entendimento um paradigma de verdade inspirado nas influências de critérios de cientificidade de René Descartes. Descartes trabalhou com o conceito de verdade enquanto adequação, uma combinação entre verdade e certeza. Destacamos que decorre desta aproximação, verdade e certeza, um ambiente de realização das experiências regido por algo exterior. Tal modo de situar homens, mulheres e suas experiências podem ser observáveis cotidianamente nas requisições por posicionamento da parte do saber psicológico assegurando que pode quantificar e medir experiências relacionais. Em Heidegger (1953/2007), o filósofo dedicou-se a compreensão da noção de verdade ressaltando-a enquanto abertura entre humanos e suas experiências considerando realidade, por exemplo, de forma aproximada a um horizonte de sentido que constituímos e somos constituídos. Assim, o filósofo alemão superou a lógica de algo exterior e acima das experiências regulando o que se trata de verdade ou não.
} 
Portanto, lemos que o filósofo evidencia o carácter ininterrupto e singular do método.

O método, presente nesse percurso, investe na necessidade de aceder reflexivamente compreensões sobre a presença da ética a partir da análise de documentos, por exemplo, os códigos são aproximados do trabalho heideggeriano sobre existência. Na ética, a constância presentificada e atualizada, revela indicativos de posicionamentos imprescindíveis à vida em comunidade. A respeito do método, encontra-se no seu delinear o reconstruir de caminhos que, a partir do tema proposto, são admitidos como caminhos éticos, modos de restituir o questionamento ao ente humano sobre seu relacionar-se e respeitar-se. Passo a passo no desvelar de que não são naturalizadas as formas como emitimos avaliações e julgamentos às sentenças, somos solicitados a intervir no cotidiano. Este cotidiano que é híbrido, envolvendo questionar-construir-criar, colabora para o edificar de compromisso ético, conjuntamente, ao exercício de normas que direcionam atividades profissionais sem abrir mão de habitarmos a ética, sintonizados com o nosso existir.

Hermeneuticamente, a compreensão é anunciada como experiência desnaturalizante, não existindo concordância com o exercício de hierarquias privilegiadas entre compreender e interpretar, já que, conjuntamente, manifestam-se. A pertinência da Hermenêutica para análises que envolvam as relações humanas demonstra-se em ocasião para que as experiências sejam acedidas ao passo em que estão sendo vividas e distanciando-se de noções que esterilizam a força da experiência ao transportá-las para tempo e espaço previamente mensuráveis.

Harmonizando compreender e interpretar, são inaugurados caminhos nos quais o desvelar dos sentidos seguem as cadências que são possíveis, e não ideais, quanto aos modos como entes humanos lidam com suas vidas, com dilemas, com sua finitude e quanto às experiências que nos envolvem, mesmo diante de cenários individualistas que nos querem fazer acreditar que existe uma única resposta, definitiva e imutável, correta e adequada e que deve ser priorizada. O contexto factual, sem restrições das questões do existir, expõe um horizonte que admitimos como horizonte do caminho ético, o qual percorremos em nossos modos de ser-no-mundo, na medida em que esse caminho ético colabora para singularizarmos os sentidos despertados e nos mobiliza aos encontros autênticos.

Investindo na dinâmica da circularidade fenomenológica heideggeriana avançamos para confluir ética como próxima a nós e, assim, suscitar nossa condição de entes humanos singulares e mobilizadores do desvelar de sentidos que nos auxiliam a nos situarmos/posicionar-nos diariamente.

\section{O comum da ética}

A ética está presente entre nós, mesmo que não percebamos $^{4}$; ademais, é instigante por posicionamentos. A tematização da ética sensibiliza observações e investigações pelo campo fértil que a envolve, isto é, as questões da existência. Como referimos, para nos permitir ser interpelados pela ética um caminho compreensivo precisa ser inaugurado, não se trata de uma escolha por método, simplesmente, como quem procura um passo a passo de como se aproximar e averiguar hipóteses. O comum da ética, tal como elegemos denominar a aproximação da ética das práticas psicológicas e de nossas experiências relacionais enquanto humanos, repousa na construção de bases que orientam, atualizando o exercício de pensar. Este outro pensar para a ética resgata o esforço por outro pensar como Heidegger (1987/2009) incentivou os interessados no método fenomenológico a se aproximarem das experiências dos pacientes que não estavam conseguindo ser apoiados pelos modos de cuidados prevalecentes no século XIX. Na seção anterior, chamamos atenção a tal feito no que dizia respeito a noção de verdade, contudo não se remete exclusivamente a esta noção, podendo inclusive nos permitir vislumbrar outros modos de compreender noções como sanidade, adoecimento etc. O modo de pensar que a ética nos convoca, a partir da leitura aqui defendida, é solicitante de um caminhar diferente ao qual estamos habituados; ao invés de averiguar, pensamos que entre existência e ética demonstram-se modos de nos mantermos em movimento, nos permitindo conduzir nossas histórias visto que, juntamente com outros entes, formamos mundo tal qual o conhecemos.

${ }^{4}$ Conforme encontramos na tese A questão da ética na psicoterapia: contribuições da Fenomenologia Hermenêutica de Martin Heidegger, Caldeira (2019). 
Ética carrega e abre precedentes não conformativos. Conciliando esta condição que relaciona a ética à formação universitária em Psicologia e à formação continuada de psicólogos, gradativamente, evidencia-se um encontro fértil para o exercício de avizinhar ética e saber psicológico em nosso dia a dia, especialmente, na clínica psicológica e no cuidado oferecido às pessoas que vivenciam algum nível de sofrimento emocional, como demonstram Borges-Duarte (2017) e Dutra \& Maux (2017).

Não podemos negligenciar o horizonte histórico que contempla as sociedades na atualidade. Os modos de viver demonstram maneiras como nos relacionamos quanto às solicitações por significados e sentidos. Evidenciar o tema da ética, sobretudo, quanto ao corriqueiro de sua presença em nossas experiências, fez-se urgente nos pós-guerras mundiais (1914-1918/19391945) e na iminência de conflitos civis que colocam em risco vidas e sociabilidade dos entes humanos. Os contextos de vida, após e no vigor destas ocorrências, tornaram-se cenários fecundos para as questões da existência adquirirem força na Psicologia, por exemplo, abrindo espaço para o que se denomina terceira força da Psicologia, a Psicologia Humanista.

Para a Psicologia, construir as suas bases e voltar a atenção às questões da existência (que se ligam a condição de humanidade, ainda mais, após as atrocidades que historicamente estamos convivendo e que abrem espaço para fenômenos relacionados ao sofrimento emocional em nosso contemporâneo, conforme Dutra e Maux $(2017,2021)^{5}$ contempla relação singular, na qual associamos a requisição de que entes humanos precisam ser compreendidos e sensibilizados do compromisso com o relacionar-se consigo e com os demais.
Na leitura que propomos, reascendemos uma noção de ética, segundo Caldeira e Dutra (2021), na qual admite-se a ética unindo entes humanos por articular as questões da existência com compromisso e quanto ao modo implicativo de assim suscitar posicionamentos. Neste caso, associamos esta articulação a um modo de compreender, e não, a reprodução simplificada de explicações que possam se encaixar nas mais diversas situações, por exemplo, como se ética se tratasse de uma norma pronta a pacificar o exercício vital de comprometimento com a vida humana e a vida na Terra. Sermos no mundo, na medida em que vivemos/experimentamos, diz respeito a ser vida que tudo movimenta, sermos movimento e construirmos nosso horizonte histórico.

Viktor Frankl ${ }^{6}$, por exemplo, ao explicitar suas ideias e compartilhar como articulou sua compreensão ao fenômeno do genocídio de seu povo, e, ainda, Hannah Arendt ${ }^{7}$ e Hans Jonas ${ }^{8}$ que elucidaram em seus trabaIhos o terror de uma humanidade que, aparentemente, havia alcançado o pior, quer dizer, a indiferença, compartilham não apenas histórias, mas sensibilizam para que questões da existência e ética não sejam relativizadas ou mesmo eliminadas.

No percurso histórico que a humanidade tem cursado, contamos, não obstante, com a ascensão do saber psicológico voltado ao aprimoramento dos testes psicológicos e avaliações psicológicas, conforme Muniz (2018) e Jesus et al. (2007), hipervalorização dos estudos de base comportamentais e inclusivamente, com os avanços expansionistas na tentativa de delimitar o que são as patologias dos transtornos mentais acrescidas em quantidades espantosas, a cada versão dos DSM's, tal como demonstrou Angell (2011); as aproximações entre Psicologia e outras

\footnotetext{
${ }^{5} \mathrm{O}$ número crescente de refugiados que se lançam por caminhos terrestres ou marítimos a fim de sair de sua região de origem. Vidas humanas que não conseguem ser mantidas e preservadas com dignidade em seus territórios de nascimento e que ao abandonar seu território sofrem humilhações, explorações e o risco de não serem aceitas em outras nações; cidadãos que em seus países não conseguem experimentar seus direitos; homens. Mulheres, jovens e crianças privadas do direito de serem cuidadas a partir da condição de vulnerabilidade que apresentam, entre inúmeros outros temas abordados nos livros organizados por Dutra e Maux $(2017,2021)$.

${ }^{6}$ Frankl (1985), “O de que o ser humano realmente precisa não é um estado livre de tensões, mas antes a busca e a luta por um objetivo que valha a pena, uma tarefa escolhida livremente. O de que ele necessita não é a descarga de tensão a qualquer custo, mas antes o desafio de um sentido em potencial à espera de seu cumprimento. O ser humano precisa não de homeostase, mas daquilo que chamo de "noodinâmica"... Ouso dizer que nada no mundo contribui tão efetivamente para a sobrevivência, mesmo nas piores condições, como saber que a vida da gente tem um sentido. Há muita sabedoria nas palavras de Nietzsche: "Quem tem um por que viver pode suportar quase qualquer como" “(p. 95-96).

${ }^{7}$ Arendt (2004), “Eles simplesmente trocaram um sistema de valores por outro" (p. 107).

${ }^{8}$ Jonas (2006), "O homem como objeto do dever inclui a responsabilidade no centro da ética, assegurando uma autenticidade humana, garantindo ao homem sua capacidade de escolha: "precisamente a preservação dessa possibilidade, como responsabilidade "cósmica", é o que significa dever de existência.

Exagerando, caberia dizer que a possibilidade de que haja responsabilidade é a responsabilidade que precede a tudo" (p.74).
} 
áreas de saber como a Neurologia; novas perspectivas de trabalho como a Psicologia Positiva, inaugurada nos anos $2000^{\circ}$, entre outros. Nesta breve exposição sobre a ascensão e diversificação do saber psicológico, demonstramos o aproximar da ética com a Psicologia ao longo dos anos e dos eventos da vida coletiva que acabam por solicitar aperfeiçoamento no modo de cuidar e conduzir mecanismos e protocolos que garantam a melhor adaptação da vida que construímos no mundo. Seja no que se refere aos relatos questionadores e implicativos quanto à condição humana, seja no aprimoramento por controle e previsão dos comportamentos dos entes humanos, a semelhança do que Jesus et al. (2007) demonstraram, o que se passa é que sobrevém convivermos numa corrida pela manutenção da vida. Inclusivamente, neste sentido o diálogo entre ética e saber psicológico pode derivar em questionamentos para o saber e profissão Psicologia, por exemplo: como convivermos conosco e com/no mundo posto que o senso de coletivo é ameaçado pelo interesse de poucos?

\section{Quando nomeamos esta seção de o comum da ética} trata-se de elucidar o caráter da ética de proximidade a cada um dos entes humanos. Ao defendermos o comum da ética não é o mesmo que dizer sobre suas semelhanças com estatutos, e sim, dar voz ao questionamento: "quão éticos somos?", ao passo que nos movimentamos sobre e com o mundo. Enquanto somos mundo e a vida deste planeta que habitamos, o que é possível na defesa da justiça, compaixão, cidadania, respeito, liberdade e cuidado? 0 comum da ética, em nossos modos de ser, chama a atenção ao quão próximos e distantes estamos de nós e dos demais, igualmente, de nossa limitação em nos refugiarmos a testes, normas, protocolos afastando-nos, pessoal e profissionalmente, do humano que conseguimos ser para estarmos conectados com o que interessa.

Ademais, o comum da ética se trata de uma ressalva nossa às possibilidades da ética, de maneira que esta não seja remetida a um uso, inclusive um uso direcionado ao banimento de problemas e adversidades, como se fosse possível a suspensão das dinâmicas da vida exigentes da nossa correspondência na medida em que nos posicionamos e correspondemos. Ser a vida que movimenta tudo a nossa volta, ser o próprio movimento, é admitir responsabilidades, que até mesmo os requeridos padrões, aos quais a Psicologia enquanto ciência e profissão enfrenta, nas tentativas em que é requisitada a intervir, por exemplo, ao precisar hábitos (mais ou menos adequados) para regulamentar um lugar social, são exigentes de um posicionar ético. Contudo, nos mantermos atentos a presença da ética entre nós, clínicos ou não, não é uma tarefa trivial. Nossa atenção, enquanto entes humanos, é modo de valorar a vida que movimentamos. Sucessivamente, sermos éticos nos recorda de que os requeridos padrões de normalidade e adaptação ao convívio em sociedade nada dizem, se não pudermos compreender que nosso sentir e agir não estão parados à espera de uma norma externa que nos diga "como", "onde" e o "porquê" de agir como agimos.

Em defesa de uma ética presente e atualizada, nossos caminhos não se tornam mais claros ou previsíveis. Nossos caminhos tornam-se, possivelmente, mais familiares, uma vez que neste mistério de transitoriedade que envolve a vida humana nada está concluso ou à espera de ser salvo. O comum da ética é a possibilidade incessante e limitada de movermos vida, apesar dos esforços de acautelar à espera de uma explicação.

Na continuidade do comum da ética, que não quer dizer unidade ou essência, e que se aproxima de assumirmos nosso lugar de movimento e força de vida na medida em que convivemos uns-com-os-outros, retomamos pontos importantes da história, fundamentação filosófica da ética, pois nesta digressão acreditamos traçar caminhos possíveis no diálogo com a ética seja para o saber psicológico seja no cuidado das relações humanas.

\footnotetext{
${ }^{9}$ A Psicologia Positiva e a crescente onda de terapias alternativas que se baseiam em não retomar o humano aquilo que o constitui, mas apaziguar e abrandar o sofrimento emocional com o intuito de nos fortalecer, retoma-nos em um erro crasso não é a infantilização de fingirmos que não existem problemas. A Psicologia, independentemente, dos diálogos a outros saber necessita encontrar meios para possibilitar-nos suportar sofrimentos, aprender a conviver, empoderar-nos enquanto entes humanos donos de nossas histórias e não desligados dos sofrimentos, da vida que temos, e daqueles que estão ao nosso redor.
} 


\section{Caminhos possíveis no diálogo com a ética}

Três caminhos se desvelam na evidenciação da ética e em seu diálogo com os códigos. No primeiro, destacamos uma breve história filosófica da ética de como influenciou o código de ética profissional na Psicologia e prevenimos para o despontar desse instrumento que coloca ética enquanto destruidora de impasses. No segundo, evidenciamos ética e código profissional como importantes argumentadores que embasam formulação de critérios e de valores, e quanto a importância desses feitos para orientações de vida. No terceiro, que entendemos não excludente de outros caminhos, atua como proposição, na qual ética é evidenciada por nos auxiliar, clínicos e não clínicos, quanto aos modos de habitarmos mundo.

No desenvolvimento da Filosofia, a ética tem sua história alicerçada em Aristóteles ${ }^{10}$ difusor da ética nos moldes como atualmente é reconhecida, enquanto disciplina filosófica. A valorização do bem-estar acrescentando liberdade e responsabilidade são heranças aristotélicas na formulação dos códigos deontológicos presentes entre as ciências modernas, por exemplo, o código de ética da Psicologia no Brasil.

Socialmente agimos e distinguimos nosso modo de nos relacionar conosco e com os demais a partir de ações ordenadas, na direção daquilo que pretendemos executar ou planejar. Interessado nas condutas humanas, Aristóteles (1825/2015) uniu esforços para aceder à felicidade, no sentido de que as ações humanas fossem direcionadas a conduzir a vida para a felicidade. Essa encontrar-se-ia apoiada em posicionamentos e comportamentos virtuosos, isto é, excelência. Aristóteles sistematizou a ética de maneira que esta possibilitasse uma vida boa felicidade e/ ou autorrealização. O trabalho do filósofo colabora para a primazia da ética, que parte do entendimento de que a razão está ao dispor humano e, ao mesmo tempo, a ética dirige a compreensão afetada/sensibilizada a partir das experiências, assim, a felicidade exigiria de nós cultivo da razão e das emoções.
A ideia de humano, enquanto uma noção prática, é princípio de ação e, igualmente, a ele é destinada atenção quanto ao seu fim, ou seja, limite. É no agir que o humano pode cumprir sua possibilidade como ser ético. A ação é a produção humana e nisto consiste seu sentido. Conforme Aristóteles (1852/2015): “o saber prático é adquirido apenas quando se converte em acção realizada. Isto é, não importa saber apenas qual é a possibilidade extrema do humano, mas saber como essa possibilidade, existir nela, de acordo com ela se tornar excelente. Saber o que fazer não é o suficiente. Tem de se agir" (p. 11).

A ética aludida nos códigos advém, de modo geral, para nos auxiliar em nosso agir de maneira que possamos aprender a lidar com nós mesmos. Na leitura aqui desenvolvida, ressaltamos que Aristóteles propagou uma ética que não visa o meio-termo, a ação ética demonstrar-se-ia nos movendo a pensar e tomar condutas e não para equilibrar as partes.

Da ética que nos conduz diariamente e que nos exige tomar orientações em nossas vidas às exigências e complexidade social, acabamos requisitando uma ética que atue como ética do dever. O principal representante da ética do dever foi Immanuel Kant. O filósofo moderno trabalhou na defesa do dever que ecoasse respeito pelo humano e aquilo que o constitui. A ética kantiana difundiu, fatalmente, a universalidade na qual apenas a razão nos permitiria conhecer as circunstâncias/contextos possíveis. Nesse sentido, a razão é o que justifica a possibilidade do princípio supremo da moralidade (imperativo categórico). O imperativo categórico, um sinal a respeito do conhecimento, é imperativo porque nos alcança como uma ordem e categórico porque é extensível racionalmente sem considerar primordial uma adequação entre a finalidade e o objetivo. A fórmula da lei universal kantiana sintetizava que nossas ações fossem tomadas de maneira que pudessem tornar-se lei universal, além disso, suas máximas valem como princípios.

${ }^{10}$ Discípulo de Platão (filósofo do período clássico da Grécia Antiga); sistematizador da ética como disciplina filosófica. 
Conforme Kant (1785/2014), a moral emergiria dos processos de culturalização nos quais somos socializados. Esta propensão a fim de que nossas ações fossem baseadas nas possibilidades de serem convertidas em leis universais, apresentam um direcionamento kantiano de que o ser humano é capacitado a se autorreger, a partir do regimento de fim em si. O filósofo moderno auxilia-nos a distinguir moral e ética, remetendo-nos a moral e sua relação direta com a cultura de cada organização social sendo esta fonte de discernimento quanto aos valores dos grupos, para a moral há modos de sermos éticos, enquanto modos de nos colocar, relacionar e avaliar a influencia de nossos valores cotidianamente. A ética, em Kant (1785/2014), presencia o entendimento em relação a felicidade no qual não há possessão ou dependência. Se expõe recusa à ética quando esta é sintetizada a uma concordância benéfica, cujos princípios de moralidade estão apoiados de forma a favorecer apenas a alguns.

Para Kant (1785/2014), agimos contraditoriamente quando fazemos escolhas opondo-nos a atingir nossos fins, ou quando, perante contextos, nos conformamos a aplicações opostas à razão, negligenciando ao reconhecimento do que estaria a conduzir nossas escolhas e preferências, pois a razão prática é o que protege a moralidade que mantém seu lugar de importância para as relações humanas e não sendo demonstrada como inferior ao exercício ético. O filósofo expôs nossa preocupação cotidiana em universalizar conhecimento a partir de casos particulares que diriam respeito à moral, valores culturais diretamente relacionáveis a uma sociedade e que não necessariamente condizem ao ser ético de forma generalizada.

A lei universal kantiana observa a humanidade hospedando a noção de respeito. Ser racional, imperativo kantiano, possibilita representações a partir das leis, pois, para Kant, tudo reside nas representações das leis. As virtudes kantianas expostas por Adela Cortina ${ }^{11}$ salientam o serviço do cumprimento do dever (Cortina, 2003) que, por sua vez, manifestam a vivacidade dos imperativos categóricos. Kant (1785/2014) ao apresentar o seu propósito de felicidade, expôs felicidade enquanto dinâmica possibilitadora para nos apropriarmos de nossas vidas, a qual aproximamos neste artigo, que desenvolve uma leitura fenomenológico-existencial da ética, do caráter de exercitarmos ética como modo de correspondermos existencialmente.

Ética além da dimensão que formula normas e regras, apresenta dimensões que propomos como importantes a ser incentivadas, por exemplo: postura e posicionamento. A ética acionada a partir dos códigos, nem sempre é dinamizada a suas implicações de cuidado, conforme Caldeira e Dutra (2021). Chamamos atenção, considerando os códigos de ética da Psicologia brasileira, que a ética não é garantia expressiva de parâmetros e limites na intervenção acerca dos seres humanos, como se fosse possível delimitar, por exemplo, uma postura por parte do profissional, previamente, ao acontecimento dos fatos em questão.

A ideia de ética adotada através do modo como se faz presente nos códigos deontológicos é sensível aos contextos que antecedem a necessidade de reunir diretrizes e princípios no instrumento código. À semelhança da presença da ética como se esta tratasse de eliminar os impasses entre o exercício profissional e as solicitações por posicionamento morais e éticos na vida cotidiana. Apreendemos, a partir do resgate e investigação do legado dos filósofos citados, e da filósofa contemporânea a qual resgatamos para a presente reflexão, que ética expressa necessidade de posicionamento via exercício reflexivo.

A ética filosófica, enquanto Filosofia Moral, explica racionalmente a dimensão moral humana, sem incidir em dogmatismos totalizantes com os quais nos habituamos a lidar ao delimitar as experiências, em naturalmente, boas ou ruins. Cortina (2003) defendeu a ideia que as diferentes éticas aplicadas, como estas que são trabalhadas nos códigos deontológicos, contribuindo para a difusão de uma ética cívica, não são retiradas da dinâmica social e cooperam para dinamizar transformando os interesses dos cidadãos como um todo. Em Cortina (2003, 1990/2004), encontramos elementos que nos auxiliam no discernir entre ética e moral, sem depreciações, e sim ampliando compreensões de como a ética pode ser lida construindo conhecimento e promovendo práticas no que diz respeito aos modos como se posicionam frente a vida e quanto aos valores

${ }^{11}$ Referência mundial no trabalho de temas consoante ética, educação moral e cidadania. 
morais cultivados na sociedade e nas experiências que o mesmo integra. Ética global, para Cortina (2003), incentiva aquilo que Kant defendia enquanto comunidade ética com leis morais comuns.

Nesse entendimento, ética comum aos humanos desde as influências filosóficas que a relacionam, por exemplo, a felicidade, não depositariam na ética o limite das páginas que compõem códigos de éticas profissionais. Nossa atenção às temáticas que envolvem ética é oportunidade de contínua reflexão. Logo, sucintamente, a ética desde uma história sobre os modos e modelos de vida em comunidade até a atualidade continua a modificar-se, contudo, é perene no que diz respeito confrontar os entes humanos quanto a sua condição de existentes e sermos-no-mundo-uns-com-os-outros.

No tracejar do caminho eleito para expor nossa compreensão de ética dialogando com código, como vimos, não somos presenteados com uma ética que destruísse os impasses de existirmos e de estarmos uns-com-os-outros, inclusive, ressaltamos o despertar de pegadas sobre ética e códigos os quais suscitam critérios e valores como importantes orientações de como agir/viver.

O comum da ética, conforme desenvolvemos na seção anterior, caminha de forma atravessada pelo ethos, no sentido latino, pois não está dissociada das reflexões quanto ao modo de viver e com os modos como estamos vivendo. Tematizar ética nos confronta com os critérios de importância, os valores, quer dizer moral, que validam orientações para o nosso viver. Quando mencionamos a importância por critérios, necessitamos restaurar interesse por autoconhecimento e conhecimento no tocante aos critérios que embasam nossa sociedade. Atentar aos critérios expõe-nos enquanto modos de conhecer evidenciados, por exemplo, como pertencentes às relações humanas, como o humano vem se constituindo, como mulheres e homens são atravessados, quer queiram quer não, pelos aspetos sociais, econômicos, culturais e biológicos.

Segundo Arendt (2004):

as questões morais e éticas, as questões em torno da conduta individual, as regras e padrões de comportamento que permitiam distinguir o certo e o errado, assim como as experiências que estiveram na sua origem e as fundaram, contam-se entre essas coisas que se julgam permanentes e duradouras e que se revelaram de uma fragilidade surpreendente (p. 228).

Ao convidar à discussão aqui proposta, da atenção de aproximação entre ética e valores, é importante não cair no erro de equiparar ética e moral, assim como temos chamado atenção no presente trabalho.

Conhecer a distinção entre ética e moral é basilar na vida coletiva que vivenciamos. A ética nos acompanha na difusão do exercício compreensivo/reflexivo além de nos orientar em nossos deveres, ações e valores. A institucionalização da ética, enquanto disciplina filosófica, não faz dela um compêndio de certezas, muito menos, quando igualamos ética ao código de ética. Não se tratam de certezas, respostas ou, quiçá, verdades aos moldes da adequação como ressaltamos nessa discussão. A Filosofia reservou para a ética o caráter/critério de orientação resgatando tarefas primordiais da Filosofia, como o pensar e refletir, acrescida da valorização do agir, isto é, "como agir".

Na similitude que a razão influencia os modos de sermos éticos, similarmente, a razão se associa aos modos de sermos morais. De um lado, no sentido de moral encontrar-se envolvida pela razão prática, no que Ihe concerne aos hábitos, logo moral distancia-se de ética, pois o hábito pertencente a moral não requisita implicação. De outro, tal como verificamos ética compreende um exercício contínuo, a razão que se aproxima com mais ênfase da ética é a razão reflexiva. As razões práticas e reflexivas, cada uma à sua maneira, são recursos compatíveis ao ente humano de maneira a este poder transformar de modo suportável o viver cotidiano. Quando referimos Aristóteles e Kant, e os modos como estes filósofos alicerçaram suas éticas, estávamos a trabalhar no sentido de discernir ética e moral. Afirmar que ética e código embasam critérios e valores que nos orientam em nossas práticas cotidianas, converge a proposição de Cortina e Martinéz (2005) de que ética e moral estão relacionados com as normas. São as normas, a requisição dessas que relacionamos com aproximações e distanciamentos entre ética e moral. Em Cortina (2003), podemos observar que moral se relaciona às ações concretas e à ética, e indiretamente normatiza às ações cotidianas. Deste modo, reavivamos a convocação da filósofa ao exercício reflexivo inclusive do campo moral. 
Não podemos esquecer que a moral é fonte de inspiração aos códigos de princípios e conduta pessoal/coletiva. Na moral recai anúncio sobre nós, nossas preferências e valores, aquilo que nos torna entes humanos semelhantes aos demais entes. Cortina (1990/2004) defende a ideia de que a moral trabalha como uma espécie de saber racional que ajuda a nossa capacidade de compreensão humana, como saber prático, para atuarmos pontualmente, e que acabamos projetando para que a moral possa atuar de forma alargada nos eximindo do exercício reflexivo da ética, especialmente, quando estamos destacando uma ética de inspiração fenomenológico-existencial que se mostra dinâmica e atualizada com o existir humano, isto é, de modo irrepetível, correspondente e envolvido de sentido. Um exemplo que aqui aludimos, diz respeito a Cortina (1990/2004) em sua investigação a Kant sobre fins morais, seriam estes contributos para o exercício de nossa humanidade no sentido de criarmos e seguirmos leis. Em Cortina, encontramos a defesa de uma ética que auxilia na compreensão da dimensão moral humana, ou seja, uma ética que inclusive nos orienta considerando os costumes, sem remetê-los a fatos naturalmente dados que não possam ser questionados ou modificados. Na defesa desta ética reflexiva que une atenção aos aspectos racionais e afetivos anunciamos, influenciados pela filósofa contemporânea, às alternativas de lidar com dificuldades, direta e indiretamente, ligadas ao viver.

Na Psicologia (ciência e profissão) temos acompanhado, nos últimos anos do século passado e início deste século, o interesse na sistematização do desenvolvimento moral. As referências que resgatamos para esta reflexão se apoiam na base cognitivista de Piaget (1932/1994) e Kohlberg (1981/1992). Os estudiosos dedicaram-se aos estudos relacionados a infância na tentativa de poder regular e antecipar decisões morais presentes ao longo da vida. Hodiernamente, a pesquisadora Gilligan (1982/1993) implementa discussões que ampliam os estudos de Piaget, principalmente, ao considerar as questões de gênero.

Ética e moral, na atualidade, são atravessadas por questões que modificam aspectos formais e universais quanto ao valor das metas, as noções de um eu, de um nós e do que concebemos por outro. Ética e moral são atualizadas quanto a convenções que as sentenciavam a posse de uma natureza cognitivista.
Ao refletir, implementamos um exercício não meramente cognitivo e ao qual somos convocados na ética a orientar-nos ao passo em que integramos sentir e pensar, raciocinar e afetar-se, e, no que diz respeito a esta modalidade de conciliação, somos desafiados urgentemente.

Após percorrermos dois dos caminhos propostos dedicamo-nos a ética auxiliando habitarmos mundo. Esta ética presentifica à insuficiência de resumirmos ética a questão da normatividade. Ética e códigos profissionais não antecedem ao ente humano. Deste modo, anunciamos uma compreensão de que é via entes humanos, clínicos e não clínicos, quer atentos quer distraídos à temática das relações humanas, que advém ética, normas e os modos como convencionamos gerir estes constructos e nossas vidas com demandas urgentes e concretas.

Com o despontar das ciências modernas e do privilegiar do pensar metafísico que prioriza a formulação e execução de critérios científicos naturais, decorreu uma naturalização gradual e perene da formulação que razão (cognição/prática) concentrava as forças do absoluto saber. Consequentemente, os entes humanos ocupam, conjuntamente com as ciências modernas, lugar de destaque, o que quer dizer que estes entes detinham absoluto saber acerca de suas vidas e sobre demais entes, e natureza na medida em que demonstrassem sua desenvoltura e poderio com a formulação de leis, normas e critérios.

Aparentemente, pulamos os questionamentos sobre o "porquê" de não abrirmos mão das leis e dos protocolos para vivermos em harmonia com nossos saberes científicos e com aqueles saberes que somente são possíveis no convívio/ relações. Erro, mudanças, transitoriedades são os itens mais temíveis na tentativa de nos mostrarmos absolutos e insubstituíveis, isto é, no cultivo de critérios científicos. Ao mesmo tempo que são temíveis, estes itens revelam possibilidades de autoconhecimento e conhecimento sobre nosso viver, nossa integração social, logo, os modos como temos investido em nossa leitura de mundo, quer dizer, o mundo que estamos construindo. Socialmente somos refletidos nas noções de acerto e erro que são institucionalizadas. As normas, as leis, os códigos são exemplificativos de nossa tentativa perene de controlar, exercer controle a fim de eliminar semelhanças quanto aos modos de existir, possibilidades que 
nos constituem e nos fazem únicos, demonstráveis em Jesus et al. (2007), Angell (2011), Muniz (2018), Caldeira e Dutra (2021).

Entramos, neste último item de nossa argumentação, no movimento de alertar quanto aos perigos de instrumentalizarmos a ética e concebermos um tipo de humanidade que subverte o que lhe é próprio, a fim de ser abonada da condição de existir. Nesta seção, defendemos uma ética como possibilidade de nos implicarmos e não nos permitir ser igualados a objetos a forjar utilidade insubstituível.

Instrumentalizar a ética e as condutas humanas não deixa de ser um modo de controle, domesticação e exploração, quase como se pudéssemos esquecer que somos finitos. Ética e códigos deontológicos não são díspares, ao ponto de impossibilitar diálogos. Ética e códigos não são sinónimos e não podemos substituir um pelo outro. Ética e códigos nos possibilitam diálogos e contribuem para harmonizar relações, por exemplo, ente humano e técnica. Ultrapassar uma tentação legalista que não restrinja ética ao instrumento código, como pode ser visto na Psicologia brasileira, no que diz respeito a posição de condicionante para a eficácia profissional. Ética e normas não abrem mão de cooperação/correspondência, sem cair em voluntarismos. Não é sobre uma ética voluntarista que nos dedicamos, dessas que são utilizadas apenas na conveniência das situações, por exemplo, "com meus pacientes sou exigente, sugiro às regras, exemplifico-as, não sou flexível a exceções; em contrapartida, diariamente, alimento posicionamentos preconceituosos, defendo que as pessoas devem ser mais ativas e menos vítimas; valorizo comportamentos que centralizam relações em pessoas mais ativas, não me importo com consumos etc.".

A narrativa que encerrou o parágrafo anterior é livre, no sentido de pode ser atribuída a inúmeras pessoas, suas variações poderiam ser encontradas nos diálogos em séries, telenovelas, filmes ou pela vizinhança, nesta narrativa exemplificamos modos de sermos nas relações que nos escapam, na maior parte das vezes, quanto a presença da ética. Por cooperação/ correspondência, anteriormente referida, coadunase reflexão e ação, e não são preestabelecidos contextos. A narrativa aludida e a referência à correspondência enquanto existencial compreendemos que se fazem presentes cotidianamente quanto aos nossos pensar e agir, profissionalmente e pessoalmente, expõem nossos modos de sermos éticos. Ser éticos, cooperativamente, nos convoca às fundamentações de nossos saberes para que ao não dissociar vida e obra possamos galgar acentuadamente confiança e implicação naquilo que somos e fazemos.

A ideia usualmente difundida de que a ética pode acabar com as adversidades diz sobre a necessidade que socialmente privilegia uma ética que nos proteja e assegure. Mas, por que reivindicamos, muitas vezes, este papel para a ética? Voltamos a questão do transitório, conforme a leitura de uma ética de inspiração fenomenológico-existencial aqui defendida, na qual a ética entre nós fundamentada nas questões da existência, tal qual associamos ao trabalho do filósofo em Heidegger (1927/2012). Nosso convite a pensarmos e nos demorar num ente humano aberto a cada vez a ser um, cuja dinâmica nos atemoriza, distancia-se de nossas tentativas de verdade/adequação como referimos. Priorizarmos os aspectos científicos da Psicologia, reiterando seu lugar de legitimidade na sociedade, não desimplica seus profissionais de atenção à manutenção e compreensão da condição humana que o assiste, e não apenas aos seus objetos de investigação.

Desde a Declaração de Direitos Humanos (1948), podemos acompanhar interesse quanto ao humano que culturalmente cada sociedade acaba moldando. Nesta declaração fica evidente que a condição humana se encontra envolvida por uma atmosfera de vulnerabilidade que não se restringia ao período pósguerras, contudo, evidencia-se, nesse (pós) período, nossa vulnerabilidade que ao tentar burlar a transitoriedade nos coloca, cada vez mais, à serviço da produção científica, leiam, técnica.

Este aspecto da vulnerabilidade humana foi observado por Jonas (2006), como relacionada a responsabilidade pela vida. Jonas (2006) salientou a condição vivida humanamente, no pós-guerra, situou-nos numa sociedade tecnológica que tem em seu centro o homem, posicionamento não compatível frente solicitações, as quais somos convocados. Alertarmos neste artigo quanto ao modo como nos relacionamos com a técnica não ser um feito exclusivo do que Jonas (2006) defendeu. Heidegger (1959/2007), similarmente, ocupou-se desta tarefa de alertar quanto a relação que dinamizamos com a técnica, entretanto reiteramos o exercício proposto por Jonas, uma vez que, regatou o imperativo categórico kantiano de "um fim em si" 
e, que de maneira difundida, acabou por influenciar diferentes códigos de condutas profissionais.

Ao ressaltar a influência da técnica sobre a condição humana, especialmente, a relação técnica e humanidade, lançamos o desafio de permanentemente, cuidar e zelar de nossos modos de vida. Nesta direção, nos mostrarmos mais atentos à impossibilidade de uma neutralidade ética. Por neutralidade ética, recuperamos Giacóia (1999) que defende que o fardo ético que contempla humanamente o homem não nos faculta distinção entre posse e exercício de poder quanto aos posicionamentos inerentes de nossos modos de ser e de fazer.

Conforme referimos, em Heidegger (1953/2007), o filósofo se deteve a advertir restrições da técnica às relações ameaçando inclusive nossa liberdade. Esta dinâmica faz-se presente na medida em que endereçamos à técnica o poder de aproximar/comparar entes humanos a espécies de meios para fins, “(...) a técnica não é portanto, meramente um meio. É um modo de desabrigar" (p. 380). Mesmo o desabrigo dos assuntos da existência ao qual somos conduzidos diante da hipervalorização da técnica, neste artigo, refletimos que pode impulsionar-nos a procurar nosso lugar e o lugar da técnica em nossos coletivos, desvela-se em posicionamentos nos quais cada um de nós reveja o lugar que sentencia a técnica para substituir o humano e suas relações. Para Singer (2017), ciência-técnica-ética integram uma inter-relação de orfandade, que não deixa de ser lida como desamparo, quanto a proteger o ente humano, pois acaba por reconvocá-lo a posicionar-se frente às solicitações. O alerta de Singer movimenta as reflexões/questões: como reinventar nosso lugar de entes humanos? Como arquitetar novas formas de nos responsabilizar?

Sem respostas prontas, no entanto, com conhecimento sendo construído avançamos à guisa de considerações e proposições a fim de que a Psicologia se desenvolva povoada de interesses, acentuadamente, reflexivos sem negligenciar que razão e afetos se revelam conjuntamente. Aceder aos sentidos de como cuidamos pessoalmente e profissionalmente de nós e dos clientes/pacientes é o efetivar dos exercícios compreensivos/reflexivos coerentes cognitivo e afetivamente. O desvelar do sentido do que ressaltamos para à ética e quanto ao lugar dos códigos deontológicos acende e torna acessível a experiência de estarmos uns-com-os-outros, e ao nos encontrarmos sintonizados e coerentes quanto ao sentido que a cada vez nos é requisitado, que possamos ampliar nossa apropriação quanto aos nossos modos de sanidade emocional e, assim, habitarmos mundo de modos livres, responsáveis e cuidadosos.

\section{Considerações finais}

As considerações a este artigo estão distantes de se apresentarem conclusivas e admitimos há limitações neste estudo. Nesta direção, mantém-se vivas as questões: o que se desvela importante quando articulamos ética e códigos? e qual a mudança que conseguimos mover?

Nas limitações de abranger uma compreensão unívoca quanto ao diálogo ética e códigos defendemos que há outros pontos possíveis de serem elucidados e convidados ao diálogo com este presente artigo para futuros trabalhos. Ao mesmo tempo, reforçamos nosso compromisso em suscitar novos estudos, enriquecer a produção de conhecimento em Psicologia e ressaltar a necessidade de novas investigações.

Através deste trabalho compartilhamos nossos esforços de contribuir para o desenvolvimento da Psicologia e acreditamos que nossa tarefa propõe um convívio com conclusões mutáveis e aproxima-nos com atenção e cuidado do desvelar dos limites que humanamente somos desafiados diariamente. Contudo, diante do inóspito do comum nos mantemos abertos a uma proximidade com aquilo que realmente importa, com o moldar dos sentidos e significados para fazer do saber prático um aliado do saber cognitivo, reflexivo e afetivo. Somente, conjuntamente, o ente humano consegue pousar e construir suas bases de maneira que diante do transitório não se renda amedrontado e, sim, mobilize ânimo, o apreender de forças para renascermos ao despontar de novos dias. As indeterminações e nossos esforços por compreender o ente humano em seu cotidiano pessoal e profissional revelam-se oportunidades de sermos éticos e, nesta conjuntura, atualizamos através deste artigo esforços de através do saber psicológico compreender cada vez mais nossa condição humana. 
Na experiência do encontro/cuidado que a clínica psicológica nos possibilita, os impasses permanecem, continuamos a orquestrar critérios e valores, tentando discernir quais nos sensibilizam e quais deles são em nós impelidos. Permanecemos procurando/ construindo auxílio para habitar mundo, organizar nossa casa, experimentar repouso e orientar como nos movimentamos faz parte dos exercícios diários de dialogar a respeito da ética comum a cada um de nós, seja ela ressaltada nos códigos seja nos modos de nos relacionar uns com os outros.

\section{Contribuições dos autores}

Caldeira DGS participou da concepção, delineamento e redação e do artigo científico. Dutra EMS participou orientação, delineamento e redação do artigo científico. Guedes participou da revisão do artigo científico.

\section{Conflitos de interesses}

Nenhum conflito financeiro, legal ou político envolvendo terceiros (governo, empresas e fundações privadas, etc.) foi declarado para nenhum aspecto do trabalho submetido (incluindo, mas não se limitando a subvenções e financiamentos, participação em conselho consultivo, desenho de estudo, preparação de manuscrito, análise estatística, etc.).

\section{Referências}

Angell, M. (2011, Agosto). A epidemia da doença mental. Revista Piauí. https://piaui.folha.uol.com.br/materia/a-epidemiade-doenca-mental/

Amendola, M. (2014). História da construção do Código de Ética Profissional do Psicólogo. Estudos em Psicologia, 14(2), 660-685. http://pepsic.bvsalud.org/scielo.php?script=sci arttext\&pid=S1808-42812014000200016\&lng=pt\&t|ng=pt

Aristóteles. (2015). Ética a Nicómaco (5a ed., A. C. Caeiro, Trad.). Quetzal. (Texto original publicado em 1852).

Arendt, H. (2004). Responsabilidade e julgamento. Companhia das Letras.

Azevedo, A. K. S. (2013). Não Há Você sem Mim: Histórias de Mulheres Sobreviventes de uma Tentativa de Homicídio [Tese de Doutorado, Universidade Federal do Rio Grande do Norte]. Repositório UFRN. https://repositorio.ufrn.br/jspui/ handle/123456789/17399
Borges-Duarte, I. (2017). Mesura e desmesura em Heidegger. Studia Heideggeriana, 6, 65-102. http://hdl.handle. net/10174/22573

Caldeira, D. G. S. (2019). A questão da ética na psicoterapia: contribuições da Fenomenologia Hermenêutica de Martin Heidegger [Tese de Doutorado, Universidade Federal do Rio Grande do Norte]. Repositório UFRN. https:// repositorio.ufrn.br/jspui/handle/123456789/27358

Caldeira, D. G. S., \& Dutra, E. M. S. (2018). Caminhos Possíveis entre Ética e a Psicoterapia fenomenológica existencial. PSI UNISC, 2(2), 35-50. https://doi.org/10.17058/psiunisc. $\mathrm{v} 2 \mathrm{i} 2.11770$

Caldeira, D. G. S., \& Dutra, E. M. S. (2021). Atualizações fenomenológico-hermenêuticas do cuidado para um corresponder ético. In E. M. S. Dutra \& A. A. Maux (Orgs.), Pesquisa em psicologia fenomenológico-existencial: interpretações do sofrimento na contemporaneidade II. CRV.

Conselho Federal de Psicologia. (2005). Código de Ética Profissional do Psicólogo. https://site.cfp.org.br/wp-content/ uploads/2012/07/codigo-de-etica-psicologia.pdf

Cortina, A. (2003). El quehacer público de la ética aplicada: ética cívica transnacional [El quehacer público de la ética aplicada: ética cívica transnacional]. In A. Cortina \& D. García-Marzá. Razón pública y éticas aplicadas. Los caminos de la razón práctica en una sociedad pluralista. Tecnos.

Cortina, A. (2004). Ética sin moral [Ética sem moral]. Tecnos. (Texto original publicado em 1990).

Cortina, A., \& Martinéz, E. (2005). Ética (S. C. Leite, Trad.). Loyola.

Dutra, E. M. S., \& Maux, A. A. (Orgs.). (2017). Pesquisa em psicologia fenomenológico-existencial: interpretações do sofrimento na contemporaneidade. CRV.

Frankl, V. E. (1985). Em busca de sentido (W. Schlupp, Trad.). Vozes.

Freire, P. (2013). Pedagogia do Oprimido. Paz e Terra. (Texto original publicado em 1972)

Giacóia Junior, O. (1999). Hans Jonas: Por que a técnica moderna é um objeto para a ética. Natureza Humanam, 1(2), 407-420. http://pepsic.bvsalud.org/scielo.php?script=sci arttext\&pid=S1517-24301999000200007

Gilligan, C. (1993). In a different voice: Psycological theory and women's development [Em uma voz diferente: A teoria psicológica e o desenvolvimento da mulher]. Harvard University Press. (Texto original publicado em 1982). 
Heidegger, M. (1979). Sendas Perdidas ( $3^{\mathrm{a}}$ ed., J. R. Armengol, Trad.). Losada.

Heidegger, M. (2007). Heidegger. Ensaios e conferências (E. C. Leão, G. Fogel \& M. S. C. Schuback, Trads.). Vozes. (Texto original publicado em 1953).

Heidegger, M. (2009). Seminário de Zollikon (G. Arnold \& M. F. A. Prado, Trads.). Vozes. (Texto original publicado em 1987)

Heidegger, M. (2012). Ser e tempo. (F. Castilho, Trad.). Vozes/ Unicamp. (Texto original publicado em 1927).

Jesus Junior, A. G., Bighetti, C. A, Freitas, F. A, Oswaldo, Y. C., \& Noronha, A. P. P. (2007). Avaliação psicológica e ética: um estudo com universitários. Universitas: Ciências da Saúde, 5, 1/2, 61-74. https://doi.org/10.5102/ucs.v5i1.267

Jonas, H. (2006). O Princípio Responsabilidade: ensaio de uma ética para uma civilização tecnológica (M. Lisboa \& L. B. Montez, Trads.). Contraponto. (Texto original publicado em 1979)

Kant, I. (2014). Fundamentação da Metafísica dos Costumes. Textos Filosóficos. (Texto original publicado em 1785).

Kohlberg, L. (1992). Psicología del desarrollo moral [Psicologia do desenvolvimento moral]. Desclée de Brouwer. (Texto original publicado em 1981)
Mattar, C. M. (2017). Prefácio. In R. N. Sá. Para além da técnica: ensaios fenomenológicos sobre psicoterapia, atenção e cuidado (pp. 7-10). Via Verita.

Maux, A. A. B., \& Dutra, E. M. S. (2020). Pensando o Círculo Hermenêutico como um Caminho para a Pesquisa em Psicologia. Estudos \& Pesquisas em Psicologia, 20(4), 10341048. https://doi.org/10.12957/epp.2020.56649

Muniz, M. (2018). Ética na Avaliação Psicológica: Velhas Questões, Novas Reflexões. Psicologia: Ciência e Profissão, 38 (spe), 133-146. https://doi.org/10.1590/1982-3703000209682

Organização das Nações Unidas. (1948). Declaração Universal dos Direitos Humanos. UNICEF. https://www.unicef.org/brazil/ declaracao-universal-dos-direitos-humanos

Piaget, J. (1994). O Juízo Moral na Criança. Summus. (Texto original publicado em 1932)

Sá, M. T. (2016). Psicologia, psicanálise e formação em educação: Reflexões sobre uma ética do olhar, quando se trata de pensar o humano. In V. Cláudio (Org.). Psicologia e Ética: O primado do humano (pp. 1, 165-176). Fim de Século.

Singer, P. (2017). Ética no mundo real: 82 breves ensaios sobre coisas realmente importantes. Edições 70.

Sousa, P. R. (2016). O ensino da ética em Psicologia. In V. Cláudio (Org.). Psicologia e Ética: O primado do humano (p. 21-50). Fim de Século. 